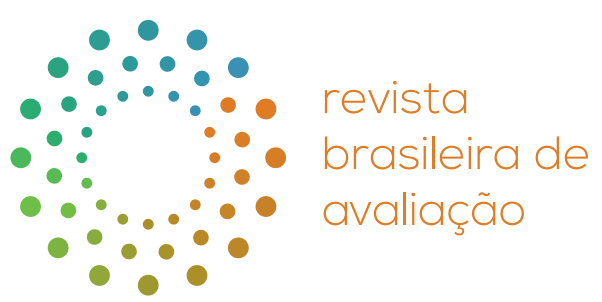

\title{
É preciso ampliar a produção teórica e prática sobre avaliação no Brasil
}

\section{The need to expand evaluation theoretical and practical production in Brazil}

Rogério Renato Silva (Branco) ${ }^{1}$ (D), Ana Maria Carneiro (Branca) ${ }^{2}$, Carolina Imura (Branca) ${ }^{3,4}$

${ }^{1}$ Pacto Organizações Regenerativas, São Paulo, SP, Brasil

2Universidade Estadual de Campinas (UNICAMP), Núcleo de Estudos de Políticas Públicas, Campinas, SP, Brasil

${ }^{3}$ Rede Brasileira de Monitoramento e Avaliação, Brasília, DF, Brasil

${ }^{4}$ Fundação João Pinheiro, Belo Horizonte, MG, Brasil

COMO CITAR: Silva, Rogério Renato, Carneiro, Ana Maria, \& Imura, Carolina (2021). É preciso ampliar a produção teórica e prática sobre avaliação no Brasil. Revista Brasileira de Avaliação, 10(2), e101221. https:// doi.org/10.4322/rbaval202110012

A ciência aplicada foi sempre essencial ao desenvolvimento da civilização. Ao enriquecer nossa experiência de vida, fazer avançar a produção econômica, apoiar a garantia de direitos e melhorar a política e a gestão, a prática científica ganhou status privilegiado nas sociedades modernas, o que lhe permitiu acumular capital político e obter financiamento público e privado. No caso brasileiro a situação não é diferente. Ainda que, por aqui, a ciência sempre tenha enfrentado inimigos ferozes, o Brasil tem elevada produção teórica e empírica em diversas áreas de conhecimento, sendo responsável por cerca de 3\% das publicações mundiais, um terço delas em colaboração internacional, segundo dados da Plataforma Scival. Ao lado das commodities que brotam de seu solo, o país também exporta teorias, modelos, métodos, técnicas e saberes de elevada utilidade para outras nações.

Quando focalizamos este debate em avaliação, o cenário é semelhante. A produção teórica e empírica brasileira é respeitável, especialmente quando se trata de estudos localizados em campos de saber consolidados como educação, saúde, meio ambiente e economia. Mas dois aspectos parecem diferir nesta comparação, apresentando desenvolvimento menor do que o necessário. Um deles diz respeito à base axiológica das avaliações, ou seja, às maneiras como os objetos de estudo são valorados, aí incluindo temas morais, políticos, estéticos, culturais, etc. O outro diz respeito ao uso das avaliações, ou seja, ao sentido que adquirem e aos efeitos que produzem nos atores sociais e na realidade.

Em termos de axiologia e uso das avaliações há muito o que avançar em ao menos três frentes. A primeira delas requer que a comunidade avaliativa amplie seu interesse e compromisso com as teorias e mecanismos de valoração que utilizam. Enquanto alguns movimentos apostam na primazia dos indicadores como orientadores técnicos suficientes para balizar os exercícios de valoração, a análise axiológica requer que outras perguntas sejam realizadas: qual é a fonte dos indicadores e critérios utilizados para balizar o exercício valorativo? A partir de quais atores os critérios emergem e qual é a razão de sua preponderância? Os critérios se apoiam em traços éticos, morais, culturais ou institucionais válidos ao objeto de estudo e a seu contexto? Há violência e exclusão quando alguns critérios são utilizados em detrimento de outros?

A segunda delas demanda atenção ao uso das avaliações. Para além de alimentar visões unívocas sobre o uso pragmático, o campo está convidado a superar a ideia de que as avaliações se limitam a produzir insumos para decisões, cultivando-as em suas várias possibilidades: reconhecer e explicar situações, fomentar aprendizagem, aproximar atores,
A RBAVAL apoia os esforços relativos à visibilidade dos autores negros na produção científica. Assim, nossas publicações solicitam a autodeclaração de cor/etnia dos autores dos textos para tornar visível tal informação nos artigos.

Recebido: Junho 15, 2021 Aceito: Junho 18, 2021

*Autor correspondente: Rogério Renato Silva

E-mail: rogerio@pacto.site

\section{(c) $\mathbf{B Y}$}

Este é um artigo publicado em acesso aberto (Open Access) sob a licença

Creative Commons Attribution, que permite uso, distribuição e reprodução em qualquer meio, sem restrições desde que o trabalho original seja corretamente citado. 
fazer denúncias e advocacy, desenvolver grupos e organizações, retroalimentar processos de implementação, formar sujeitos, etc. Para isso, parece oportuno que a comunidade avaliativa se abra a tais perspectivas e possa reconhecer, investigar e sustentar as variações de sentido e de utilidade que as avaliações podem assumir para atores diferentes em culturas, contextos e momentos diferentes. Se apenas um sentido é permitido, é provável que se esteja a operar num registro autocrático com efeitos deletérios ao interesse público e ao fortalecimento da democracia.

O uso das avaliações requer também o exame da relação entre a produção e o uso de evidências na formulação e implementação de iniciativas. Se a gestão baseada em evidências tem sido tema uníssono em muitos campos, a comunidade avaliativa tem tratado pouco das dinâmicas e mecanismos de poder que definem o modo como as decisões são realizadas e regulam o consumo de evidências. Em outras palavras, muitas avaliações têm sido pensadas a partir de referenciais que tratam técnica e política como variáveis dissociadas, o que lhes marca com certa ingenuidade, deixa-Ihes a caminhar em círculo em torno da primazia da técnica e Ihes alija dos processos políticos reais.

É tomando as perspectivas axiológica e de uso das avaliações que lançamos um chamado à comunidade avaliativa para ampliar sua produção teórica e empírica nestes temas. Refletir sobre o modo como as avaliações valoram os objetos e sobre como as avaliações são utilizadas no cotidiano da sociedade será de grande relevância à avaliação no Brasil e contribuirá para um campo mais denso, diverso, crítico e engajado em temas centrais ao desenvolvimento, à redução das desigualdades e ao fortalecimento da democracia. 0 aprimoramento metodológico para produzir estudos mais sensíveis a complexidade de agendas que desafiam a sociedade parece estar na valoração e no uso das avaliações a possibilidade de colocá-las a serviço de agendas estruturais ao futuro: renda mínima, pacto federativo, relações público-privadas, investimento público, regeneração ambiental, entre outras temáticas essenciais para reduzir as desigualdades e assegurar o combate ao racismo e a promoção da equidade entre gêneros.

E se a produção teórica e empírica está na base dos avanços necessários, é também preciso que os espaços formativos sejam ampliados e se abram mais diretamente às pautas da valoração e do uso das avaliações. Para além de ofertas formativas que ensinem técnicas e manualizem as avaliações, as formações devem se mover não apenas na direção de formar profissionais de avaliação, mas na direção de sensibilizar e preparar aqueles a quem as avaliações se destinam, tais como gestores, ativistas, dirigentes, jornalistas, parlamentares e técnicos. Se são estes os atores dos quais emergem os critérios de valoração e se são eles os que fazem escolhas e decisões, não pode haver dúvidas de que a evolução da potência das avaliações no Brasil requer o preparo de avaliadores, mas também o preparo de interessados em avaliação.

Em tempos de tamanhos desafios, está claro quanto esforço será necessário para produzir novas agendas e amplificar aquelas já em curso. Mas é preciso avançar. Está claro também que o tempo pandêmico fez crescer a demanda por instituições mais fortes e por modos de gestão baseados na transparência e na responsabilidade e inequivocamente comprometidos em assegurar direitos fundamentais a todos os brasileiros, a começar pelo direito à vida. No percurso que está sendo trilhado, são evidentes os potenciais da avaliação para fortalecer as instituições e a gestão, mas também evidentes os obstáculos que precisam ser superados para que tais potenciais possam ser realizados. Ampliar o debate público sobre o papel das avaliações, bem como a capacidade dos agentes lançarem mão das avaliações como instrumento de luta, parece compor o signo avaliativo dos próximos anos.

Fomentando reflexões nessa direção, esperamos que a entrevista, artigos, ensaios e relatos de experiência apresentados neste volume da Revista Brasileira de Avaliação possam ser examinados na perspectiva da valoração e do uso, e que tal exame estimule mais pessoas à formação, às práticas avaliativas cotidianas e à produção de mais literatura. Esperamos que o chamado que trazemos neste editorial movimente o campo na direção de mais diálogo, produção e reflexão dado o compromisso desta revista: promover o uso das avaliações 
em temas de interesse público para contribuir para a garantia de direitos civis, políticos, ambientais e sociais no Brasil, o aprofundamento da democracia e o uso inteligente de recursos públicos e privados.

\section{Fonte de financiamento:}

Não há.

\section{Conflito de interesse:}

Não há. 